\author{
ARTIGO \\ COI htps://doi.org/10.22481/praxisedu.v15i36.5901
}

\title{
A FORMAÇÃO CONTINUADA DOCENTE A SERVIÇO DE FORMAR-SE PARA OS PROCESSOS ESCOLARES INCLUSIVOS
}

\author{
CONTINUING TEACHER TRAINING AT THE SERVICE OF FORMATION FOR THE \\ INCLUSIVE SCHOOL PROCESSES
}

\section{LA FORMACIÓN DOCENTE CONTINUA: EL SERVICIO DE FORMACIÓN PARA LOS PROCESOS ESCOLARES INCLUSIVOS}

\author{
Mayara Costa Silva \\ Universidade Federal do Rio Grande do Sul - Brasil \\ Clarissa Haas \\ Instituo Federal do Rio Grande do Sul - BRASIL
}

\begin{abstract}
Resumo: O presente estudo de abordagem qualitativa aborda a formação continuada de professores relacionada à Educação Especial na perspectiva da Educação Inclusiva. A interlocução é construída por meio de levantamento bibliográfico envolvendo a produção acadêmica da área. Faz-se a seguinte problematização: Quais conhecimentos podem caracterizar o fazer docente para os processos escolares inclusivos? Os apontamentos da literatura acadêmica manifestam que prevalecem os modos de conhecer instrumentalistas e desconexos da reflexão no espaço escolar. A partir da investigação, afirma-se como diretrizes da formação continuada docente para os processos escolares inclusivos: o trabalho colaborativo entre os agentes escolares o conhecimento pedagógico por meio da articulação entre teoria e prática; e a valorização do espaço de reflexão docente nos cotidianos.
\end{abstract}

Palavras-chave: Educação especial. Educação inclusiva. Formação continuada docente.

\begin{abstract}
The present study of qualitative approach deals with the continuing teacher training related to Special Education in the context of Inclusive Education. The interlocution is built through a bibliographical survey involving the academic production of the area. The following problematization is made: which knowledge can feature the teaching for inclusive school processes? The notes from the academic literature show that those ways of knowing which are instrumentalist and disconnected from reflection prevail in the school space. The following continuing teacher training guidelines are stated, from research, for the inclusive school processes: the collaborative work among school agents, the pedagogical knowledge through articulation between theory and practice and the value of space for teacher reflection in everyday situations.
\end{abstract}

Keywords: Continuing teacher training. Inclusive education. Special education. 
Resumen: El presente estudio cualitativo, aborda la formación continua de los profesores vinculados a la Educación Especial desde la perspectiva de la Educación Inclusiva. A partir de la indagación que se realizó a la bibliografía específica del área, surge la siguiente pregunta de investigación: ¿Cuáles conocimientos caracterizan la práctica docente en los procesos escolares inclusivos? La literatura académica evidencia que pueden existir diferentes maneras de identificar a los docentes en los espacios de reflexión, entre ellas: los instrumentalistas e incoherentes. A partir de esta investigación, se enuncian algunas pautas para la formación continua docente en los procesos escolares inclusivos como son: el trabajo colaborativo entre los agentes escolares, el saber pedagógico por medio de la articulación entre la teoría y práctica, así como la valorización del espacio de reflexión docente en su cotidianidad.

Palabras clave: Educación especial. Educación inclusiva. Formación continua docente.

\section{1 “FORMAR-SE” EM FORMAÇÃO CONTINUADA' DOCENTE}

A formação docente (em especial os percursos formativos continuados) esteve fortemente presente na agenda política das gestões públicas municipais e estaduais, principalmente no intervalo de 2003 a 2015, com o Programa Federal Educação Inclusiva: Direito à Diversidade ${ }^{2}$, do Ministério da Educação, com vistas à implementação da Política Nacional de Educação Especial na perspectiva da Educação Inclusiva (BRASIL, 2008) nos contextos escolares.

A Lei de Diretrizes e Bases da Educação Nacional - Lei nº 9394, de 20 de dezembro de 1996 (BRASIL, 1996), ao tratar dos profissionais da educação, afirma como o primeiro fundamento a ser garantido com relação à formação de professores a associação entre teorias e práticas, inclusive mediante a capacitação em serviço. Nesse sentido, observa-se, a partir deste documento normativo, a valorização de um processo de formação continuada que deriva do cotidiano escolar e que tem por princípio a associação entre teoria e prática.

Atualmente, no Brasil, existem duas possibilidades formativas para atuação do professor responsável pelo Atendimento Educacional Especializado: a formação inicial que envolve a licenciatura em educação especial ou uma formação inicial em qualquer licenciatura seguida de uma formação continuada na área da educação especial. Segundo a Resolução 04 de 2009 (BRASIL, 2009), que estabelece diretrizes para o atendimento

\footnotetext{
${ }^{1}$ Compreendemos, no âmbito do presente estudo, a formação continuada como possibilidade de reinvenção das práticas pedagógicas, ou seja, a formação continuada como potencializadora dos processos de ensinoaprendizagem na escola. Deste modo, a pesquisa realizada trata como sujeitos destinatários da formação continuada tanto os professores do ensino comum, professores especializados em educação especial, equipe pedagógica das escolas; ou seja, todos os profissionais da educação são considerados para esse estudo decisivos na efetivação do sistema escolar inclusivo.

${ }^{2}$ Programa ministerial que teve como principal objetivo apoiar a formação de gestores e professores com vistas a tornar os sistemas de ensino inclusivos.
} 
educacional especializado (AEE) na educação especial na educação básica, com vistas a atuar no AEE o professor deve ter uma formação inicial que o habilite para a docência, além de ter formação na área da educação especial.

Destacam-se, entre as atribuições elencadas na Resolução 04 de 2009 (BRASIL, 2009), aquelas que propõem a articulação e parceria entre este professor e os professores da sala de aula comum, bem como com outros serviços, o que caracteriza o serviço como algo que se deveria ser baseado na colaboração e no diálogo.

O ingresso daquele que aprende em modos e tempos "diferentes" ao ideal de homogeneização expresso na maioria dos currículos escolares produz os pilares da problematização sobre a relação entre os conhecimentos e os saberes e fazeres docentes para os processos inclusivos. Portanto, nesse estudo, ao questionarmos quais conhecimentos devem balizar o fazer docente para os processos escolares inclusivos, buscamos mais do que construir respostas. Nosso intuito é fortalecê-las e ampliar a reflexão em torno da formação continuada docente para a Educação Inclusiva articulada aos modos de conhecer.

\section{OS CONTORNOS DA LITERATURA ACADÊMICA}

Buscando um olhar ampliado da produção acadêmica no cenário nacional sobre a formação continuada docente para a educação especial na perspectiva da Educação Inclusiva, debruçamo-nos como fonte principal de pesquisa no Portal de Teses e Dissertações da CAPES, no período de 2001 a 2017; e como fonte complementar nos Anais dos IV e V Seminários Nacionais de Pesquisa em Educação Especial (SNPEE, 2008-2009). Elegemos os anais do seminário de dois anos consecutivos (2008 e 2009), por identificarmos a significativa presença da discussão da formação continuada, compondo-se como eixo temático nessas edições. Além disso, compreendemos o referido evento como importante espaço de discussão para a área da educação especial, tendo em vista a interlocução entre diferentes grupos de pesquisa e diferentes investigadores de diversos estados no âmbito nacional.

\subsection{Mapeamento das pesquisas no Portal de Teses e Dissertações da CAPES}

Inicialmente, foi realizado o mapeamento das pesquisas no Portal de Teses e Dissertações da CAPES sobre a formação continuada em geral, o que nos levou a 163 diferentes pesquisas. Após a leitura analítica dos trabalhos encontrados em busca de 
investigações que se relacionassem mais intimamente com a temática discutida, chegamos a um total de 59 produções $^{3}$. Propusemos a aproximação entre as investigações com base nos seguintes eixos:

a) políticas de formação continuada docente - Leodoro (2008), Buiatti (2013), Silva (2014a), Silva (2014b), Ferreira (2015), Marostega (2015), Silva (2009), Vieira (2010), Matos (2011), Oliveira (2012), Oliveira (2002), Silva (2008), Silva (2010), Fernandes (2011), Lehmkuhl (2011), Leitão (2008), Silva (2013), Correa (2013), Valadão (2013), Harlos (2015), Sá (2014), Silva S. C. G. C (2014), Cardozo (2015), Fiorini (2015);

b) pressupostos teórico-metodológicos sobre a formação continuada docente Martins (2007), Hummel (2012), Almeida (2014), Reis (2016), Monteiro (2016), Possa (2013), Leitão (2008), Guasselli (2014), Regiani (2009) Ivanovici (2005), Dal Forno (2005), Nascimento (2008), Souza (2008), Ribeiro (2008), Machado (2009), Queiroz Jr. (2010), Leite (2007), Martins (2010), Piovezani (2013), Nozi (2013), Alves (2013), Nunes (2013), Galvis (2014), Camargo (2014), Silva J. P. (2014), Silva (2014), Silva (2010), Otalara (2014), Silva (2016), Vilaronga (2014), Rabelo (2012), Peixinho (2016), Rabelo (2016), Galvis (2014), Silva (2015).

Com relação à primeira categoria de análise, tecemos algumas considerações, buscando articular as pesquisas encontradas, com o objetivo de traçar um panorama acerca das políticas articuladas à formação docente e educação especial no Brasil.

O Programa "Educação Inclusiva: direito à diversidade" foi alvo das pesquisas realizadas por Leodoro (2008), Matos (2011) e Oliveira (2012). Leodoro (2008) analisa as características da formação ofertada para os professores, utilizando-se dos materiais de apoio produzidos a partir desta iniciativa e publicados nos anos de 2004 e 2007. Segundo a autora, este programa pode ser apontado como um "avanço" com relação às políticas de formação continuada de professores. Esta mudança de perspectiva torna a educação inclusiva responsabilidade de diversos atores sociais - estados, municípios, escolas, gestores e educadores, apontando indícios da responsabilidade pública na formação de professores de educação especial e da necessidade de aperfeiçoamento contínuo na temática da inclusão.

Os estudos de Matos (2011) e Oliveira (2012) buscaram compreender a política de formação de professores proposta no âmbito do referido Programa Ministerial e sua influência no trabalho dos professores. Oliveira (2012) ao analisar as iniciativas de formação continuada

3 Entre as produções destacadas, algumas coincidem com o levantamento feito nos Anais dos IV e V SNPEE, e por isso, não serão aqui repetidas. 
decorrentes do Programa mencionado, tece algumas críticas com base na visão dos professores participantes.

As políticas de formação de professores responsáveis pelo AEE foram o foco das análises propostas por Silva (2008), Sá (2014), Silva (2014a) e Silva (2014b). Silva (2008) questionou sobre qual a influência dos processos de formação continuada oferecidos pela Secretaria de Educação do Estado de Mato Grosso - SEDUC-MT - para o aprendizado da docência de professores de educação especial ${ }^{4}$. Conforme o autor, as professoras, que em sua maioria não tiveram, no âmbito da formação inicial, a abordagem de aspectos relacionados à educação especial, indicam que as ações de formação continuada oferecidas pela SEDUC-MT e a vivência em sala de aula são os principais constituintes de suas aprendizagens para a docência. $\mathrm{O}$ autor discute, nesse sentido, a importância de olhar para o contexto de atuação do docente como potencializador de uma formação que se constitui a partir da reflexão e da prática cotidiana.

A pesquisa de Sá (2014) teve como lócus a rede municipal de ensino de Nova Iguaçu Rio de Janeiro (RJ) e se desenvolveu a partir de um grupo focal com duas professoras responsáveis pelo AEE e uma das coordenadoras da educação especial no município. Segundo a autora, as professoras apontaram fragilidades em sua formação inicial e destacaram a importância da formação em serviço, além de indicarem a não oferta de formações por parte do município. Todas enfatizaram, ainda, a importância de formações continuadas voltadas a todos os professores, não apenas aos especialistas.

No mesmo sentido, Silva (2014a) também olhou para as políticas de formação de professores a partir das salas de recursos multifuncionais do município de Porto Velho, Rondônia (RO), voltando-se à formação inicial e continuada dos professores que atuam na rede estadual no AEE neste município. Dentre os apontamentos realizados pela autora, há destaque para a formação continuada de professores como espaço para a qualificação e aprofundamento do trabalho realizado no campo da educação especial, bem como sobre a importância da experiência de cada docente nesse sentido. Além disso, de forma mais global, aponta-se para a importância de se pensar em políticas públicas específicas acerca do lócus prioritário para a formação destes professores.

\footnotetext{
${ }^{4}$ Os trabalhos analisados empregam inúmeros conceitos para fazer referência ao professor de educação especial, como "professor de sala de recursos", "professor de atendimento educacional especializado", entre outros. Ao longo do trabalho, utilizaremos o conceito de "professor de educação especial" ou "professor responsável pelo atendimento educacional especializado", por compreender que este serviço é muito mais amplo que o espaço da sala de recursos multifuncionais, não se restringindo a ela.
} 
O lócus de pesquisa de Silva (2014b) envolveu o contexto do município de Catalão Goiás -, de 1999 a 2012. A autora olhou para o perfil do profissional envolvido com o AEE, as propostas formativas desenvolvidas no âmbito do contexto em questão, as características dessas formações e o conjunto de políticas promovidas pela Subsecretaria Regional de Educação de Catalão. Foi possível compreender algumas características da própria rede de ensino, como a necessidade de haver licenciatura em Pedagogia para atuar no AEE, o que não se exige no âmbito nacional para ingresso deste profissional. De acordo com a pesquisadora, as ofertas de cursos da referida rede estadual de ensino, focaram nas tipologias de deficiência e deixaram a desejar quanto a uma formação crítico-reflexiva. Percebeu-se a queda na promoção desses cursos entre 2006 a 2011, bem como, a partir de 2006, o aumento dos cursos configurados na modalidade de educação à distância (EAD). A partir das narrativas construídas pelos profissionais, pode-se compreender que existiu a possibilidade, por intermédio da pesquisa colaborativa, de avaliar as ações formativas: "elas perceberam que, para além de uma formação pragmática, cumulativa e fragmentada, é possível pensar uma formação continuada em que a reflexão sobre a própria prática pedagógica se tona o eixo condutor do processo educativo" (SILVA, 2014b, p. 178).

Vieira (2010) analisa como a formação continuada ofertada para escolas públicas da rede estadual do Pará contribui para a prática pedagógica desses docentes no processo de inclusão dos alunos com deficiência. Segundo o autor, as professoras puderam repensar suas práticas de maneira reflexiva.

Silva (2010) analisou as contribuições oportunizadas pelo Curso em EAD intitulado Formação Continuada de Professores para o Atendimento de Alunos com Deficiência Mental aos professores que realizaram a formação para reflexão sobre a transformação dos seus conhecimentos acerca da inclusão escolar. A autora afirma que houve modificação e ampliação dos conhecimentos por parte dos docentes em decorrência do curso, bem como, a mudança de postura por parte dos cursistas frente à diversidade. Além disso, o curso, de modalidade EAD, proporcionou a inclusão digital dos participantes. Silva (2013) abordou a temática das políticas de inclusão escolar relacionadas à formação de professores tomando como lócus a rede municipal de ensino de Petrópolis (RJ). Destacam-se, entre inúmeras questões levantadas pela autora, a fragilidade da formação inicial no campo da educação especial, a importância de formações continuadas no âmbito da escola e ainda a ausência de reflexão acerca das práticas pedagógicas desenvolvidas. 
Ferreira (2015) analisa quais os caminhos que conduzem os professores ao trabalho na educação especial, na área da deficiência visual, e a relação com as experiências formativas propostas pelo Instituto Benjamin Constant (RJ). Ao analisar a relação das trajetórias dos processos e o plano político, critica o fato de ter havido um aumento expressivo de matrículas de alunos com deficiência nas escolas públicas e de ter-se mantido a baixa oferta de formação continuada na área. Além disso, a autora oferece destaque para a relação entre a formação docente e as práticas pedagógicas, bem como, a importância da troca de experiências entre docentes.

As pesquisas de Marostega (2015) e Corrêa (2013), a partir de diferentes análises, dedicaram-se à formação de professores e ao atendimento de alunos surdos. O curso de formação de professores de Educação Especial da Universidade Federal de Santa Maria (RS) é objeto de investigação de Marostega (2015). A autora apresenta a seguinte questão norteadora: quais discursos e como esses constituíram os currículos de formação de professores de educação especial para alunos surdos na UFSM? A investigação pautou-se especificamente em sete currículos do curso de formação de professores desenvolvidos entre 1962 e 2009. A autora afirma que os eixos centrais verificados nos discursos presentes nos currículos constituem-se entre a saúde, a pedagogia e a educação especial. No início de 1962, estes currículos se encontraram baseados na área da saúde com disciplinas, em sua maioria, voltadas para este campo e sem disciplinas pedagógicas; a partir de 1973 passam a ser da Pedagogia, tendo em vista que se constituíam a partir da habilitação em pedagogia; e apenas no início de 1984 possuem uma maior vinculação com a Educação Especial, quando se constitui o curso de licenciatura na área, conforme existe hoje no contexto da universidade analisada. Conforme Marostega (2005), nos currículos reformulados em 2004 e 2008, esmaeceram-se os discursos a respeito de cada uma das deficiências o que no ponto de vista da autora repercutiu em uma fragilidade na formação na área da surdez. Percebe-se, nesse sentido, que a tese está centrada em questionar se o campo da Educação Especial deve continuar sendo o lócus da formação de professores surdos.

Lehmkuhl (2011) analisou a formação continuada para educação especial oferecida no âmbito da Fundação Catarinense de Educação Especial (FCEE) entre os anos de 2005 e 2009. Para o autor, a maioria dos cursos foram oferecidos para as instituições especializadas em educação especial, e focavam as deficiências e os recursos do ensino-aprendizagem. Também foram oferecidos cursos aos professores da rede regular de ensino, pautados nos princípios 
que fundamentam a educação inclusiva. Entretanto, segundo o autor, foi possível perceber que os cursos baseavam-se ainda nas vertentes médico-pedagógica e psicopedagógica.

A dissertação de Correa (2013) buscou analisar as repercussões de uma formação continuada de professores envolvendo a LIBRAS para a escolarização de alunos surdos na escola comum. Segundo a autora, a formação continuada foi pensada a partir da percepção do despreparo de muitos professores para o atendimento dos alunos surdos, tanto na sala de aula regular quanto na sala de recursos. O lócus de estudo envolveu 20 professores da rede municipal de ensino de Manaus, dos quais 10 atuantes em sala de aula regular e 10 nas salas de recursos multifuncionais. A autora conclui afirmando as fragilidades existentes nos cursos de formação inicial de professores para o atendimento a alunos com deficiência, principalmente o aluno surdo. A partir disso, destaca o papel fundamental da formação continuada e relata que um curso de LIBRAS significou o início do interesse dos professores na inclusão de alunos surdos.

Fiorini (2015), buscou aplicar e analisar uma proposta específica de formação continuada. A formação, voltada para professores de Educação Física, teve como objetivo promover o acesso a recursos de tecnologia assistiva para o trabalho com alunos com deficiência e autismo. A autora destaca alguns fatores primordiais para o desenvolvimento da formação: atenção ao contexto e às necessidades apontadas pelos professores; valorização do trabalho colaborativo; e a possibilidade de haver espaços de reflexão e planejamento das práticas pedagógicas desenvolvidas pelos docentes. Além disso, reitera-se a importância da tecnologia assistiva como suporte fundamental.

A pesquisa desenvolvida por Leitão (2008) em municípios do Espírito Santo envolveu 17 professores e buscou compreender quais aspectos foram relevantes na constituição dos mesmos como professores de educação especial. A autora conclui que a graduação e as condições sociais e históricas de vida desses docentes são aspectos que influenciam no percurso formativo docente. Além disso, segundo os professores envolvidos na pesquisa, são também pontos importantes a vivência e a experiência propiciadas pelo cotidiano escolar.

O estudo realizado por Fernandes (2011) avaliou o Curso de Formação de Professores do CIEP 179 - Professor Cláudio Gama/São João de Meriti (RJ). A discussão central tratou da educação inclusiva com vistas a combater a exclusão escolar e as possibilidades oferecidas pela formação do professor para a prática da inclusão escolar de pessoas com deficiência. As

${ }^{5}$ Centros Integrados de Educação Pública. 
conclusões da presente investigação destacam a utilização de dispositivos, como a adaptação curricular.

Harlos (2015) buscou analisar os cursos de pedagogia e os cursos de pós-graduação lato sensu ofertados no estado Paraná, de forma a compreender se estavam em sintonia com a atual política nacional de educação especial (2008) e qual o perfil docente nela exposto. O autor destacou, como uma das fragilidades, que os cursos analisados não têm oferecido a possibilidade de práticas pedagógicas ou estágios na área. Na mesma linha, Silva (2009) analisa a Habilitação em Educação Especial do curso de Pedagogia da Faculdade de Filosofia e Ciências da UNESP, A autora utiliza-se do Projeto Político Pedagógico e do Plano de Ensino do Curso de Pedagogia como espaço de análise para embasar o argumento do que seria "perdido" com a extinção da habilitação específica em Educação Especial. Compreendese, segundo a autora, que os cursos de formação lato sensu, ou seja, por meio de especializações, seriam "reducionistas", na medida em que incentivam professores de outras áreas a atuarem e ocuparem-se do AEE para os alunos com deficiência. Segundo a autora, a política de formação inicial e continuada é frágil, tendo em vista que cursos à distância, de pós-graduação em serviço - cursos de especialização lato sensu - não atendem às necessidades de lecionar especificamente cada tipologia de deficiência, e que a alternativa mais coerente para a formação deste profissional seria o curso exclusivo de Habilitação em Educação Especial.

Os trabalhos seguintes, inserem-se no segundo eixo de análise elencado e se aproximam quanto à discussão das perspectivas teóricas e metodológicas que deverão subsidiar as ações de formação continuada docentes, destacando-se os conhecimentos docentes necessários para implementar os processos inclusivos.

A utilização de tecnologias assistivas e diferentes recursos tecnológicos vinculada à formação de professores de educação especial foi pauta das pesquisas de Hummel (2012), Almeida (2014), Reis (2016) e Monteiro (2016). É unânime entre as pesquisas a percepção da ausência do trabalho com as tecnologias assistivas, tanto como temática prioritária no âmbito das formações ofertadas, quanto para possibilitar que os professores qualifiquem o trabalho dentro da escola.

As pesquisas de Ivanovici (2005) e Dal Forno (2005) têm aspectos de conexão. Ambas analisaram, de forma específica, os conhecimentos que devem constituir a formação dos professores de alunos com deficiência. Porém, Ivanovici (2005) utilizou um conceito de formação continuada vinculado a processos formais. Já para Dal Forno (2005), que trabalha 
com uma perspectiva de formação a partir do cotidiano docente, por meio da investigação realizada com professores no município de Santa Maria (RS) foi possível perceber que os docentes constroem seus conhecimentos na vivência, com base na prática e nas experiências em sala de aula, o que contribui para a percepção da escola como espaço potencial na formação de professores e da temporalidade como elemento que influencia essa relação. Silva (2014b), em sintonia com a proposta desenvolvida no âmbito do presente estudo, olhou de forma específica para o perfil dos professores envolvidos com a educação inclusiva em uma escola pública no município de Natal (RN), objetivando, de forma prioritária, analisar as concepções de inclusão destes docentes e as necessidades formativas apontadas por eles com relação ao espaço da inclusão escolar. Segundo o autor, entre as considerações tecidas, dentre os docentes participantes, a grande maioria (90\%) não possui nenhuma formação ligada à educação especial, o que repercute diretamente nos processos escolares inclusivos.

A representação e a percepção de professores acerca das formações às quais tiveram acesso foi alvo de análise da pesquisa de Nascimento (2008), Ribeiro (2008), Leitão (2008), Nunes (2013) e Regiani (2009). Na investigação de Nascimento (2008), tendo como foco a formação continuada em educação especial, tomam-se como referência duas escolas públicas do município de Macapá (AP). A autora apontou a insatisfação das professoras com as formações continuadas oferecidas, pois em sua maioria conteúdos tratados são predefinidos e descontextualizados. Ribeiro (2008) também se pautou na percepção dos professores sobre a escola como espaço de formação continuada. em uma escola municipal da cidade de São Pedro do Sul (RS). Segundo a autora, os professores ainda percebem como formação continuada as palestras trazidas por gestores, sendo necessário um trabalho coletivo entre o corpo docente da escola para modificação dessa cultura.

Nunes (2013) analisou as propostas de formação continuada na área da educação especial ofertadas pela SEDUC do município de Ariquemes, Roraima (RO). A análise se desenvolveu a partir da percepção das professoras que participaram dos cursos e daquelas que atuaram na organização. O objetivo principal da pesquisa envolveu "compreender como profissionais envolvidas na formação continuada em Educação Inclusiva, desenvolvida pela rede estadual de ensino em Ariquemes-RO, no período de 2002 a 2011, analisam essa formação" (NUNES, 2013, p. 17). A autora afirma que houve indicações de entraves para a realização dos cursos tanto por parte das participantes quanto das organizadoras. As organizadoras apontaram, entre outras questões, o desafio de desenvolver propostas de curso que atendessem a todos. Os professores indicaram que os cursos raramente alcançavam as 
propostas em suas necessidades e pareciam fora de contexto. No entanto, segundo a autora, levando em consideração que estas têm sido as únicas iniciativas formativas às quais as professoras têm tido acesso, os cursos são considerados importantes na medida em que influenciaram o atendimento aos alunos com deficiência.

O estudo apresentado por Regiani (2009) investigou a possível relação ente formação, percepções e as práticas pedagógicas de professoras especialistas em Educação Especial atuantes nas classes comuns das séries iniciais com alunos com deficiência. A investigação tomou como lócus a Rede Municipal de Educação de Londrina. A análise dos dados obtidos a partir de entrevistas semiestruturadas resultou em sete categorias de análise a respeito da experiência dos professores no atendimento a alunos com deficiência e pôde dar indícios das características de suas práticas pedagógicas. Os profissionais tiveram sua formação em Curso de Especialização em Educação Especial na perspectiva generalista e apontam como necessidade de mudança na organização curricular do curso o aprofundamento de conteúdo acerca do autismo, bem como o acréscimo de estágios. Destaca-se, ainda, que "as participantes compreenderam a importância da relação teoria e prática e consideraram positivas as práticas demonstradas em todas as áreas de deficiência abrangidas no curso" (REGIANI, 2009, p. 123). A autora destaca, ainda, a partir das práticas pedagógicas observadas. a percepção de que se faz necessário olhar as atividades planejadas para os alunos com deficiência, pois percebeu-se que "faltou um planejamento que possibilitasse compatibilizar as atividades desenvolvidas para atender às necessidades dos alunos com deficiência e os demais alunos em classe" (REGIANI, 2009, p. 124-125).

Souza (2008) buscou refletir a respeito da proposta de formação continuada do professor em parceria com a equipe interdisciplinar da Secretaria de Educação de São Bernardo do Campo, São Paulo (1996-2003). A pesquisa, desenvolvida junto aos professores que participaram dessa ação e que atuavam na educação especial, buscava identificar, entre outras questões, qual a influência da formação continuada em suas práticas pedagógicas. Segundo a pesquisadora, a partir das entrevistas realizadas junto aos docentes, tornou-se possível perceber que as situações cotidianas desafiadoras foram pauta de reflexão constante. Destacam-se que, além da parceria com a equipe da Secretaria de Educação de São Bernardo do Campo, outros fatores contribuíram no processo formativo, dentre os quais: "a organização do grupo; o fato de a escola propiciar ao professor espaços alternativos para, com a equipe, refletir situações emergenciais; o projeto pedagógico, dinamizando práticas e problematizando questões mais amplas vinculadas às relações da escola com as famílias" 
(SOUZA, 2008, p. 221). Alves (2013) e Camargo (2014) pesquisaram acerca da formação de professores vinculados às salas de recursos multifuncionais. Alves (2013), no contexto de escolas públicas estaduais de Belém, Pará (PA), investigou a formação continuada dos professores de salas de recursos e os efeitos destas em suas práticas no âmbito do atendimento educacional especializado. De acordo com a pesquisadora, dentre as conclusões tecidas, aponta-se para estratégias de formação que ainda desvinculam a teoria e a prática, priorizando a primeira, o que fragiliza tais propostas, tornando-as insuficientes, dadas as necessidades dos professores. No mesmo sentido, Camargo (2014) analisou a formação e a atuação destes professores no município de Sorocaba (SP). Houve ênfase na percepção de que mesmo que alguns programas formativos apresentem algumas fragilidades, eles são de suma importância com relação aos percursos formativos dos professores de salas de recursos, tendo em vista que ajudam a enfrentar questões cotidianas e dificuldades encontradas na prática.

As práticas pedagógicas vinculadas à inclusão escolar tiveram enfoque no trabalho de Cardozo (2015), que buscou analisar os conhecimentos dos professores acerca das políticas de inclusão escolar, objetivando levá-los a uma reflexão acerca de suas práticas na Educação de Jovens e Adultos. Aponta-se, entre outras questões, para a fragilidade das políticas públicas envolvendo a educação especial e a inclusão escolar, bem como, a importância da formação continuada de professores na área para fortalecer a implementação de políticas.

$\mathrm{Na}$ investigação desenvolvida por Machado (2009), é proposta uma reflexão acerca dos saberes constituídos também com base nas práticas pedagógicas de professoras do município de Montenegro (RS), buscando responder quais são e como podem ser construídos esses saberes para a inclusão de alunos com deficiência. A pesquisadora afirmou ser importante desenvolver processos de formação continuada, e indicou que a escola é um possível espaço de formação. O estudo de Nozi (2013) também buscou analisar os saberes considerados necessários aos professores do ensino regular com vistas à promoção da inclusão escolar a partir das pesquisas desenvolvidas na área. De acordo com a autora, os saberes recomendados e considerados fundamentais envolvem, prioritariamente, as atitudes docentes com relação à inclusão escolar, bem como os saberes práticos, teóricos e suas características subjetivas enquanto docentes.

Piovezani (2013) analisou a concepção dos professores do ensino fundamental I (anos inicias) da rede municipal de ensino de Cascavel, Paraná (PR), acerca de sua preparação para o atendimento de alunos com deficiência e sobre a formação inicial ou continuada para o campo. Os professores que participaram do estudo, em sua maioria, demonstram sentir-se 
despreparados para receber e atender o alunado público-alvo da educação especial e destacam, com relação à formação contínua, a necessidade da criação de programas de formação específicos na área voltados para a docência. Acerca da formação inicial, são apontadas inúmeras fragilidades como o pouco ou nenhum trabalho voltado para a área.

A pesquisa de Queiroz Jr. (2010) foi realizada na rede municipal de ensino de São Bernardo do Campo (SP). O autor analisou como os professores especializados em deficiência intelectual percebem as questões referentes à sua formação continuada, e investigou as iniciativas de formação continuada oferecidas pela rede municipal. Os professores apontam a necessidade de formações que relacionem teoria e prática, bem como, indicam a falta de uma formação abrangente, tendo em vista que hoje é diverso o alunado presente nas salas de recursos multifuncionais. Segundo o autor, é necessário que a Secretaria Municipal de Educação desenvolva um plano de formação consistente e coerente com suas ações e concepções.

Martins (2010) investigou quais são as características, a formação e as "concepções desejáveis" em professores que atuam junto a alunos com altas habilidades/superdotação, em uma cidade próxima ao Distrito Federal. Para esses docentes, a formação deve ser específica e continuada. Quanto ao perfil docente, foram percebidas tanto características emocionais e sociais quanto profissionais. A autora também percebeu que parte dos docentes possui algumas ideias questionáveis em relação às especificidades dessa tipologia de sujeitos, como a relação da identificação por meio de testes de Q.I (Quociente de Inteligência) e a percepção da possibilidade do desenvolvimento desses sujeitos sem a necessidade de investimento nos processos de escolarização (autodesenvolvimento). Tais concepções acerca do aluno com altas habilidades/superdotação são indicativas da pouca discussão no que diz respeito a esse grupo de sujeitos especificamente e nos oferecem pistas para refletir acerca do que vem sendo (re)produzido acerca da temática no contexto nacional.

O ensino colaborativo constitui-se como o foco das investigações de Vilaronga (2014), Rabelo (2012) e Peixinho (2016). Vilaronga (2014) apresenta o conceito de coensino como sinônimo de ensino colaborativo, afirmando que

O ensino colaborativo ou coensino é uma das propostas de apoio na qual um professor do ensino comum e um professor especializado dividem a responsabilidade de planejar, instruir e avaliar o ensino dado a um grupo heterogêneo de estudantes. (VILARONGA, 2014, p. 20) 
Partindo do argumento de que o coensino contribui diretamente e pode vir a ser uma formação para as práticas pedagógicas voltadas ao ensino-aprendizagem de estudantes com deficiência, delineia-se a pesquisa apresentada pela autora. As experiências do ensino colaborativo na rede municipal de ensino de São Carlos foram objeto de análise e de extração de elementos para a proposta de uma formação para os professores de educação especial. A proposta de coensino assumiu um cunho de política pública, sendo inserido no Plano Municipal de Educação do município em questão, influenciando a continuidade da formação dos profissionais envolvidos com a prática, constatando-se a relevância do "caráter formativo das trocas cotidianas" (VILARONGA, 2014, p. 179). Cabe destacar que a autora afirma, ainda, a importância de não vermos a discussão acerca da formação do professor responsável pelo atendimento dos alunos com deficiência descolada do contexto geral no que concerne à educação.

O ensino colaborativo foi tema da dissertação de mestrado de Rabelo (2012), que compreende tal como o compartilhamento de responsabilidades sobre a escolarização de "alunos com necessidades educativas especiais" entre professores da área de Educação Especial e do ensino comum. Demonstra-se, segundo a autora, que potencialidades e limites podem ser identificados no ensino colaborativo para a formação continuada de professores e a inclusão escolar. O grupo de atores tido como foco de análise foram duas professoras do ensino comum e cinco responsáveis pelo AEE, além de uma estagiária e três alunos com autismo oriundos de escolas públicas municipais do Pará.

As considerações finais de Rabelo (2012) apontam para três elementos centrais decorrentes da observação das relações entre esse grupo de atores: 1) a ausência de um "expert" na educação de alunos com autismo não impediu o compartilhamento de experiências e qualificação da prática pedagógica sobre o planejamento de rotinas, ensino de habilidades e comunicação alternativa entre os profissionais participantes; 2) existe a necessidade do estabelecimento de funções para professores de classe comum e do ensino especial e "paraprofissionais"6, bem como a identificação dos limites e possibilidades de coexistência dos dois serviços de apoio - trabalho na salas de recursos multifuncionais e ensino colaborativo -, desde que uma forma não substitua a outra; e, por fim, 3) a articulação coerente de formação de professores no contexto educacional brasileiro seria aquela que compreende o ensino colaborativo como a possibilidade de compartilhamento de práticas e

\footnotetext{
${ }^{6}$ Segundo a autora, os paraprofissionais atuavam como apoio junto às professoras da sala de aula comum do ensino regular que tinham algum aluno com deficiência. Estes profissionais eram estudantes de licenciatura em pedagogia e tinham vínculo de estagiários.
} 
demandas correlacionadas às rotinas e à vida dos participantes, e deveria estar em coexistência com aquela na qual exista como objetivo a constituição de discussões filosóficas e políticas a respeito da educação, objetivando uma sustentação teórica para o trabalho em consonância com a "mobilização de seus conhecimentos que podem se aprimorar e se consolidar nas experiências de colaboração e formação" (RABELO, 2012, p. 155).

Silva (2015) buscou analisar os elos entre pesquisa, formação docente e contextos inclusivos. A análise foi realizada a partir de um grupo de professores, vinculado ao programa Observatório da Educação ${ }^{7}$, que se reunia com regularidade para discutir práticas pedagógicas desenvolvidas em contextos de inclusão escolar. A partir do estudo, aponta-se para a importância de espaços dialogados de formação que coloquem os professores como sujeitos ativos no processo de formar-se, bem como a necessidade de propostas e espaços de formação que enfoquem as práticas pedagógicas e a experiência docente.

\subsection{Seminário Nacional de Pesquisa em Educação Especial e produção bibliográfica}

Também elegemos para a análise documental algumas publicações decorrentes dos Seminários Nacionais de Pesquisa em Educação Especial (2008-2009). Consideramos que o referido material sistematiza com potência narrativa os direcionamentos e as movimentações da reflexão sobre a formação docente na perspectiva da Educação Inclusiva, haja vista a sua constituição como um lugar de discussão plural, agregando diferentes grupos de pesquisa de todas as regiões do país, em um recorte temporal expressivo (2005-2011).

A importância dessa opção [a escolha pela temática de formação de professores] é facilmente percebida quando consideramos: as mudanças de perspectiva que caracterizam a educação especial contemporânea, as novas exigências em termos de saberes profissionais docentes e as incertezas sobre os espaços formativos previstos ou recomendáveis para a formação na área da educação especial. (V SPNEE, 2009, Apresentação).

Entre os trabalhos, após a leitura apreciativa de todo o material, selecionamos 10 produções que consideramos articuladas à reflexão que estamos propondo nesse estudo. Entre a temática da formação continuada docente, propomos a aproximação entre os estudos com base nos seguintes eixos: Políticas de Formação Continuada Docente (LORETO, 2008; BRIDI, 2009; BOROWSKY，2009; FRANÇA，2008; OLIVEIRA; SANTOS，2009);

\footnotetext{
${ }^{7}$ Programa instituído a partir de uma parceria entre o INEP, a CAPES e a SECADI.
} 
Pressupostos teórico-metodológicos sobre a formação continuada docente (ROZEK, 2008, 2009; BRIZOLLA, 2009; DUEK, 2009; JESUS e PANTALEÃO, 2009).

No primeiro eixo destacado, Políticas de Formação Continuada Docente, os trabalhos das autoras Bridi (2009) e Borowsky (2009) convergiram na análise de programas de formação continuada de iniciativa federal. As demais autoras destacadas analisam políticas públicas de formação continuada em redes municipais distintas no cenário brasileiro.

Bridi (2009) analisou a experiência do município de Santa Maria (RS), como polo do Programa Nacional de Educação Inclusiva: Direito à Diversidade. Especificamente foi analisado o Curso de Formação Continuada sobre o AEE, realizado pela Universidade Federal de Santa Maria em parceria com a Universidade Aberta do Brasil/Ministério da Educação (UAB/MEC), em sua segunda edição, subsidiando uma abrangência bastante ampla de professores em atuação nas escolas públicas. A autora assume uma posição cautelosa com a oferta da formação continuada na modalidade da EAD e destaca a necessidade de estudos que investiguem as características dessa formação e as mudanças provocadas no interior das escolas e das redes de ensino.

Borowsky (2009) investigou os materiais impressos do curso de formação de professores na perspectiva da Educação Inclusiva, oferecidos pelo MEC, problematizando quais as bases epistemológicas que sustentam as propostas governamentais de formação continuada para professores da educação especial. Baseando-se na análise documental, a autora entende que o material tende a direcionar a compreensão do Atendimento Educacional Especializado (AEE) como práticas instrumentalistas, e que há pouca referência sobre pesquisas que tratam do conteúdo ensinado em determinada formação, as perspectivas teóricas de determinado curso e o que se objetiva socialmente com ele.

Loreto (2008) centrou sua investigação nas políticas de formação continuada realizadas no município da Serra (ES). O autor critica as análises centradas nos fazeres de cunho essencialmente instrumentalista por parte do professor do AEE, e centra sua discussão na necessidade de articular a proposta dos cursos com o cotidiano escolar.

França (2008) apresentou uma reflexão acerca da política inclusiva no município de Cariacica (ES) e do trabalho do profissional especializado e sua importância para a implementação de uma proposta inclusiva. A autora fundamenta sua investigação na perspectiva histórico-cultural, a qual possibilita compreender o professor em seu processo de constituição profissional em relação às vivências em sociedade e às práticas discursivas. 
A pesquisa de Oliveira; Santos (2009) analisou a política inclusiva no estado do Pará, abrangendo oito redes municipais de ensino desse estado. $\mathrm{O}$ estudo investiga as estratégias diferenciadas de formação continuada realizadas pelas redes e aponta a necessidade de superar o dualismo entre saberes e fazeres. Para a autora, a educação inclusiva indica a necessidade de uma formação docente mais abrangente, envolvendo os aspectos psicossociais, éticos e políticos da educação, além dos saberes específicos voltados às singularidades e necessidades individuais dos sujeitos.

Encontramos afinidades teóricas entre o trabalho de Brizolla (2009), de Jesus e Pantaleão (2009) e Duek (2009), no que tange à compreensão do trabalho cooperativo no cotidiano escolar, como matriz epistemológica propulsora dos processos formativos.

Brizolla (2009) pôs em evidência a fragilidade do sistema escolar, mediante uma das atribuições do professor especializado: o trabalho cooperativo com o ensino comum. Conforme a autora, nos espaços escolares são facilmente encontradas as práticas pedagógicas em espaços de AEE totalmente desvinculadas dos objetivos do trabalho e do currículo da escola. A autora parte da premissa de que para haver a cooperação entre os professores especializados e do ensino comum faz-se necessária à mobilização pela formação docente permanente e progressiva, no que se refere às políticas de formação inicial e continuada.

Duek (2009) propôs a valorização do cotidiano de trabalho como espaço de aprendizagem docente, tendo a prática pedagógica como eixo central. Sua investigação baseou-se em estudos de caso de ensino realizados com um grupo de docentes em atuação em uma escola da rede municipal de ensino de Natal (RN). Para a autora, os casos de ensino apresentam potencial formativo e contribuíram para a aprendizagem docente por meio da experiência e da reflexão individual e coletiva.

Jesus e Pantaleão (2009) tomaram como objeto de análise a multiplicidade de serviços de especializados existentes dentro da rede estadual do Espírito Santo. Os autores propõem que a formação docente, em seus dois tempos, inicial e continuada, possa ocorrer de forma articulada e imbricada; priorizam a reflexão sobre as práticas realizadas no cotidiano, bem como apontam para os possíveis nos cenários de complexidade que fazem parte da referida rede; e destacam a necessidade de rompermos com a dicotomia entre educação geral e educação especial, pois esse olhar traz implicações nos processos formativos.

As investigações de Rozek (2008, 2009) também contribuem para pensar as perspectivas teóricas e metodológicas da formação continuada docente. A autora baseia sua investigação nas histórias de vida docentes, a partir do método biográfico, e menciona as 
pesquisas de Nóvoa, destacando que para o autor esse método tem duas funções: a investigação e a formação docente.

No segundo eixo proposto acerca dos conhecimentos necessários para a docência especializada em Educação Especial, os pesquisadores são enfáticos ao destacar que esses conhecimentos são de deriva pedagógica.

A sistematização elaborada nos permite perceber que a temática de formação continuada de professores tem mobilizado a produção acadêmica em todo o território nacional. Tal mobilização demonstra que as ações de formação continuada ocorreram prioritariamente nas redes municipais de ensino, como um dos reflexos do Programa Nacional de Educação Inclusiva: Direito à Diversidade.

As pesquisas em sua maioria apontam para que as ações de formação continuada não se organizem de modo puramente instrumental. Nesse sentido, é preciso que a reflexão seja fundamentada no cotidiano escolar e na escola, como lócus de formação. Ainda prevalece a organização de cursos com enfoque clínico e em práticas empobrecedoras, tais como, a adaptação curricular; algumas abordagens defendem o perfil pautado em uma formação especialista - ou seja, aquela que forma o docente com base em conhecimentos direcionados apenas para uma deficiência -, mas a maioria das pesquisas coloca-se em a favor de uma formação generalista, que se pauta prioritariamente no conhecimento pedagógico. Além disso, o trabalho cooperativo e colaborativo também é apontado como uma estratégia da formação continuada, para que esta possa ocorrer de modo permanente no espaço escolar.

\section{PARA SEGUIR REFLETINDO}

Ao longo deste estudo procuramos discutir indícios que evidenciassem possíveis respostas à questão proposta sobre a relação entre o conhecimento e a formação continuada docente na área da Educação Especial. Os achados das pesquisas analisadas, datadas de 2001 a 2017 transcenderam o marco temporal, à medida que retomam estudos realizados desde os anos sessenta acerca da formação inicial/continuada para a educação especial, mantendo e renovando algumas perguntas sobre o tema ao longo do tempo. Ao considerar as amplas possibilidades formativas no campo legal e normativo - expressas na LDBEN (BRASIL, 1996); Resolução CNE 04/2009 (BRASIL, 2009) - entendemos que, embora seja uma pergunta com a qual devemos seguir dialogando, é possível afirmar que a formação continuada docente se constitui pela reflexão das práticas pedagógicas. 
Cabe destacar que assumimos, ao longo do texto, o conceito de formação continuada associado à possibilidade de qualificação das práticas pedagógicas através da reinvenção do cotidiano escolar. Nesse sentido, corroboramos as ideias de Jesus (2006) quando afirma a formação continuada como "estruturante dos processos de repensar a escola e prática pedagógica" (JESUS, 2006, p. 104), ou seja, reiteramos, por meio dessa investigação, um lugar para a formação continuada, o qual não precisa vinculá-la, necessariamente, a processos formativos formais. Assim, a formação continuada, em nossa concepção, envolve percursos que possibilitam movimento, deslocamentos e processos de trans-formar-se.

Compreendemos a necessidade de que esse percurso seja eminentemente de deriva pedagógica, privilegiando uma discussão de cunho generalista sobre os processos escolares. Embora não tenha sido o foco desse estudo pautar com exclusividade a formação especializada para atuação junto ao público-alvo da educação especial, consideramos importante nos posicionarmos a respeito de uma formação generalista igualmente para esses profissionais. Concordando com Garcia (2011), o professor especializado em Educação Especial de cunho generalista "estaria mais inclinado ao debate pedagógico, portanto, mais próximo da escola regular, das dinâmicas curriculares, dos processos educativos comuns e, com isso, de uma tarefa de articulação mais pedagógica do que intervenção clínica" (GARCIA, 2011, p. 68). Desta forma, ao apostarmos em uma formação que prioriza o conhecimento pedagógico em detrimento de conhecimentos específicos, estaremos investindo na constituição de um docente reflexivo, que diante de desafios surgidos saberá buscar subsídios e alternativas para superá-los, e poderá tecer a análise crítica sobre suas próprias práticas pedagógicas.

Na continuidade destas ponderações, pensamos que a profissionalização docente exige novos modos de conhecer na relação de produção do conhecimento, a fim de provocar a reflexão pedagógica da forma como trata Meirieu (2005). O autor discute o conceito de "reflexão pedagógica" (MEIRIEU, 2005, p. 149), como um processo composto por quatro etapas. (1) Deve-se assumir um desafio, como fez Itard ao decidir apostar na educação de Victor de l'Aveyron. (2) É necessário reunir aporte teórico para utilizá-lo como base para a reflexão. (3) É preciso fazer um levantamento sobre quais são as contradições que permeiam a educação a partir da singularidade de cada caso. (4) Por fim, é necessário criar maneiras que possibilitem superar as contradições e os desafios, como fez Itard, ao criar ferramentas pedagógicas com o intuito de que Victor aprendesse por si mesmo. Meirieu (2005) alerta ainda que tal processo não é constituído linearmente, ou seja, ocorre de forma não definitiva. 
Entendemos que a busca por novos modos de conhecer capazes de estabelecer um olhar de reinvenção docente é possibilitada pelo trabalho colaborativo, como estratégia formativa ou de intervenção nos cotidianos escolares, tanto entre os pares docentes, como pela busca de estratégias pedagógicas que valorizem a parceria entre os discentes. Jesus (2006) aponta para a importância de percebermos que o professor não pode trabalhar sozinho, pois a "escola deve organizar-se de forma a criar condições de reflexidade - crítica individuais e coletivas" (JESUS, 2006, p. 104), de forma que se desenvolva um trabalho colaborativo.

A valorização do trabalho colaborativo é notória igualmente nos contextos educativos internacionais. Citamos o estudo de Maset (2011) em que o autor descreve a aula inclusiva como aquela em que a aprendizagem cooperativa está presente, envolvendo os estudantes em atividades nas quais sejam instigados a ajudar-se mutuamente a aprender. Pavan e Daminato (2002), ao tratar da aprendizagem cooperativa no contexto da escola italiana, concebem-na como a experiência didática baseada na possibilidade de construir junto com os alunos um contexto de escolarização centrado naquilo que o sujeito pode fazer e não só naquilo que ele não pode fazer, oferecendo assim atividades adequadas aos seus modos e tempos de aprendizagem. Argumentam também que, para além do aprimoramento das relações interpessoais que os preparam e permitem a participação na vida social, o fato de ensinarem ao colega aquilo que sabem favorece uma aprendizagem mais duradoura, à medida que os estudantes precisam desenvolver a compreensão conceitual e o aprofundamento da informação a fim de ensinar uns aos outros.

Entendemos o trabalho docente colaborativo como a mola desencadeadora dos processos de consolidação dos princípios da Educação Inclusiva, à medida que cria as condições para a articulação necessária entre o professor do ensino comum e do AEE diante da escolarização dos sujeitos com deficiência. Para Baptista, "as atribuições que implicam em articulações/conexões entre o docente do ensino especializado e do ensino comum abrem espaço para a discussão curricular necessária nos processos inclusivos" (BAPTISTA, 2011, p. $65)$.

Os apontamentos da literatura acadêmica manifestam que prevalecem os modos de conhecer instrumentalistas e desconexos da reflexão no espaço escolar; esses modos estabelecem critérios investigativos frágeis para a construção de uma cultura docente em que o despreparo e a incompletude sejam tomados como características inerentes à dinâmica de conhecer e aprender, e, logo, possam ser considerados elementos capazes de provocar movimentos, ao invés de estagnação. Ainda são poucas as produções que apontam para 
práticas formativas em que o professor é desafiado a aprimorar competências reflexivas acerca do trabalho pedagógico. Há que se registrar, também, que após a "aparente" 8 finalização do Programa ministerial Educação Inclusiva: direito à diversidade, as iniciativas de formação continuada em educação especial na perspectiva da educação inclusiva junto às redes públicas de ensino diminuíram drasticamente na sua regularidade e amplitude. Portanto, o momento político brasileiro atual requer que voltemos a questionar a quantidade das formações disponibilizadas, na mesma medida que refletimos e questionamos a qualidade ou as perspectivas teórico-metodológicas das ações formativas.

Nas palavras de Meirieu (2006, p. 44), “formar-se em formação inicial e continuada não significa outra coisa: pesquisar, construir, analisar, confrontar, com colegas e com especialistas situações de aprendizagem". Nesse sentido, é necessário que se aposte em processos formativos que valorizem a constituição do docente reflexivo, entendendo que a dinamicidade da vida e dos processos escolares tecidos no cotidiano da escola (re)posicionam diariamente a nossa necessidade de formar-se.

Desse modo, sustentamos como diretrizes da formação continuada docente, tanto em itinerários formativos formais como não formais: o conhecimento pedagógico e os saberes didáticos construídos na conexão entre a teoria e a prática como a base da docência nos processos escolares inclusivos; o trabalho colaborativo entre os agentes escolares professores do ensino comum e especializado; equipe pedagógica; estudantes - de modo que todos tenham um papel de comprometimento com a perspectiva da educação inclusiva; a formação do docente reflexivo capaz de ler o seu cotidiano como espaço potencializador e qualificador de sua prática pedagógica.

\section{REFERÊNCIAS}

ALMEIDA, Leiva Marcia Rodrigues de. Educação inclusiva: um olhar sobre a formação de professores para o uso das tecnologias nas salas de recursos multifuncionais de escolas públicas estaduais de Campos Belos - Goiás. Dissertação (Mestrado) - Programa de pósgraduação em Educação, Universidade de Brasília, Brasília, 2014. Orientadora: Prof ${ }^{a}$. Dr ${ }^{a}$ Amaralina Miranda de Souza.

8 Não foram encontrados registros oficiais quanto à finalização do Programa. Todavia, desde 2016, não há mais ações significativas realizadas por intermédio do Programa mencionado junto aos municípios polos, levando-nos a inferir sua finalização a partir desse ano. 
ALVES, Lígia Maria Acácio. Formação e práticas em sala de recurso multifuncionais de escolas estaduais referências em educação inclusiva. $153 \mathrm{f}$. Dissertação (Mestrado em Educação) - Faculdade de Educação, Universidade do Estado do Pará, Belém, 2013.

BAPTISTA, Claudio Roberto. Ação pedagógica e Educação Especial: a sala de recursos como prioridade na oferta de serviços especializados. Revista Brasileira de Educação Especial, v. 17, p. 59-76, 2011.

BERTAZZO, Joíse de Brum. Formação profissional para atuação educacional com pessoas com transtorno do espectro do autismo. 151 p. Dissertação (Mestrado em Educação) - Programa de Pós-Graduação em Educação, Linha de Pesquisa Educação Especial, Universidade Federal de Santa Maria, Santa Maria, RS, Brasil, 2015. Prof. Dr. Carlo Schmidt.

BOROWSKY, Fabíola. Formação de professores na política de educação inclusiva: análise do curso de aperfeiçoamento de professores para o AEE V Seminário Nacional de Pesquisa em Educação Especial: formação docente em foco. Anais.... UFRGS, UFES, UFSCAR, SP, 2009.

BRASIL. Ministério da Educação. Lei de Diretrizes e Bases da Educação Nacional No 9.394. MEC, 1996.

BRASIL. Ministério da Educação. Política Nacional de Educação Especial na perspectiva da Educação Inclusiva. MEC/SEESP, 2008.

BRIDI, Fabiane. IV Seminário Nacional de Pesquisa em Educação Especial: conhecimentos \& margens. Anais... UFRGS, UFES, Gramado, RS, 2009.

BRIZOLLA, Francéli. Para além da formação inicial ou continuada, a form(a)ção permanente: o trabalho docente cooperativo como oportunidade para a formação docente dos professores que atuam com alunos com necessidades educacionais especiais. Anais... $\mathrm{V}$ Seminário Nacional de Pesquisa em Educação Especial: formação docente em foco. UFRGS, UFES, UFSCAR, SP, 2009.

BUIATTI, V. P. Atendimento educacional especializado: dimensão política, formação docente e concepções dos profissionais. 320 f. Tese (Doutorado) - Programa de pósgraduação em Educação, Universidade Federal de Uberlândia, Uberlândia, 2013. Prof ${ }^{a}$. Dr ${ }^{a}$ Arlete Aparecida Bertoldo Miranda.

CAMARGO, Miriam Rosa Torres de. Salas de recursos multifuncionais: um estudo sobre a formação e atuação de professores. Sorocaba: UFScar, $117 \mathrm{f}$. Mestrado (Dissertação em Educação) - Faculdade de Educação, Universidade Federal de São Carlos, Sorocaba, 2014. Prof $^{\mathrm{a}}$. Dr ${ }^{\mathrm{a}}$ Izabella Mendes Sant'Ana.

CARDOZO, Dora Maria Couto Marques. Diálogos entre a educação especial e a educação de jovens e adultos: uma proposta de formação continuada de professores para atuar com pessoas com deficiência intelectual. Dissertação (Mestrado em Educação) - Faculdade de Educação. Universidade Federal Fluminense. Niterói, 2015. 
CORREA, Rosana Modesto. A formação continuada do professor para a educação de surdos da rede municipal de Manaus: repercussões na prática pedagógica. $135 \mathrm{f}$. Mestrado (Dissertação em Educação) - Programa de pós-graduação em Educação, Universidade Federal do Amazonas, Manaus, 2013. Prof. Dr. Aristonildo Chagas Araújo Nascimento.

DAL FORNO, Josiane Pozzatti. Imaginários e saberes docentes na escola inclusiva: um estudo dos processos de formação e autoformação. 165 p. Dissertação (Mestrado em Educação) - Universidade Federal de Santa Maria. 2005. Prof ${ }^{a}$. Dr ${ }^{a}$ Valeska Maria Fortes de Oliveira.

DUEK, Viviane. Formação de professores e educação inclusiva: uma experiência com casos de ensino. V Seminário Nacional de Pesquisa em Educação Especial: formação docente em foco. Anais... UFRGS, UFES, UFSCAR, SP, 2009.

FERNANDES, Keilla de Oliveira. Educação Inclusiva: as experiências do curso de formação de professores do CIEP179 - Professor Cláudio Gama/ São João de Meriti/ RJ. 187 p. Dissertação (Mestrado em Educação) - Universidade Federal Fluminense, 2011.

FERREIRA, E. M. B. Políticas Públicas e Formação Docente na área da deficiência visual. 162 f. Dissertação (Mestrado em Educação). Programa de Mestrado em Educação, Universidade Estácio de Sá, Rio de Janeiro, 2015.

FIORINI, Maria Luiza Salzani. Formação continuada do professor de educação física em tecnologia assistiva visando a inclusão. $157 \mathrm{f}$. Tese (Doutorado em Educação). Faculdade de Educação, Universidade Estadual Paulista, Marília, 2015. Prof. Dr. Eduardo José Manzini.

FRANÇA. Marileide Gonçalves. O trabalho do professor da educação especial como política pública no município de Cariacica. IV Seminário Nacional de Pesquisa em Educação Especial: conhecimentos \& margens. Anais... UFRGS, UFES, Gramado, RS, 2008.

GALVIS, Gloria Esneida Castrillon. (DES)encontros do professor com a alteridade do aluno da educação especial: a construção de um acolhimento. 120 f. Dissertação (Mestrado em Educação) - Faculdade de Educação, Universidade Federal do Rio Grande do Sul, Porto Alegre, 2014.

GARCIA, Rosalba Maria Cardoso. Política Nacional de Educação Especial nos anos 2000: a formação de professores e a hegemonia do modelo especializado. In: CAIADO, Katia Regina. Moreno; JESUS, Denise Meyrelles de; BAPTISTA, Claudio Roberto (Orgs.). Professores e Educação Especial: formação em foco. v. 2. Porto Alegre: Mediação, 2011. p. 65-78.

GUASSELLI, M. F. R. Formação continuada na perspectiva da educação inclusiva: epistemologia e prática. 190 f. Tese (Doutorado) - Programa de Pós-Graduação em Educação, Universidade Federal do Rio Grande do Sul, Porto Alegre, 2014. Prof ${ }^{\mathrm{a}}$. Dr ${ }^{\mathrm{a}}$ Elizabeth Diefenthaeler Krahe.

HARLOS, Franco Ezequiel. Formação de professores para educação especial no Paraná: cursos de pedagogia, pós-graduações lato sensu e políticas públicas. 229 f. Tese (Doutorado em Educação) - Faculdade de Educação, Universidade Federal de São Carlos, São Carlos, 2015. Prof ${ }^{a}$. Fátima Elisabeth Denari. 
HUMMEL, Eromi Izabel. Formação de professores de salas de recursos multifuncionais para o uso de tecnologia assistiva. $231 \mathrm{f}$. Tese (Doutorado em Educação) - Faculdade de Filosofia e Ciências, Universidade Federal Paulista Júlio de Mesquita Filho - Campus Marília, Marília, 2012. Prof. Dr. Eduardo José Manzini.

IVANOVICI, Anne. Formação contínua de professores: algumas necessidades decorrentes da inclusão. 145 p. Dissertação (Mestrado) - Universidade Braz Cubas, 2005.

JESUS, Denise Meyrelles de; PANTALEÃO, Edson. Serviços educacionais especializados: desafios à formação inicial e continuada dos profissionais da educação V Seminário Nacional de Pesquisa em Educação Especial: formação docente em foco. Anais.... UFRGS, UFES, UFSCAR, SP, 2009.

JESUS, Denise Meyrelles de. Inclusão escolar, formação continuada e pesquisa açãocolaborativa. In: BAPTISTA, Claudio Roberto. (Org.). Inclusão e escolarização múltiplas perspectivas. Porto Alegre: Mediação, 2006, p. 95-106.

LEHMKUHL, Márcia de Souza. Educação Especial e formação de professores em Santa Catarina: as vertentes médico-pedagógica e psicopedagógica como base da formação continuada. 292 p. Dissertação (Mestrado em Educação) - Universidade Federal de Santa Catarina. 2011.

LEITÃO, Maria Elisa Bittencourt. Professores que atuam na educação especial: trajetórias de vida e de formação acadêmica. 146 p. Dissertação (Mestrado com ênfase em Educação Especial) - Centro de Educação, Universidade Federal do Espírito Santo, 2008.

LEITE, Débora Lúcia Lima. Qualificar para a diversidade: avaliação da necessidade de formação continuada para professores na escola inclusiva. 109 p. Dissertação (Mestrado em Educação Brasileira) - Faculdade de Educação, Universidade Federal do Ceará, 2007.

LEODORO, J. P. Inclusão escolar e formação continuada: o programa Educação Inclusiva: direito à diversidade. 128 p. Dissertação (Mestrado em Educação) - Universidade de São Paulo. 2008.

LORETO, Sulamar Snaider. Formação continuada de professores: uma ação política no município da Serra na perspectiva inclusiva IV Seminário Nacional de Pesquisa em Educação Especial: conhecimentos \& margens. Anais... UFRGS, UFES, Gramado, RS, 2008.

MACHADO, Glaé Côrrea. Caminhos para a educação inclusiva: a construção dos saberes necessários na formação e na experiência dos professores do município de Montenegro/RS. 145 p. Dissertação (Mestrado em Educação) - Universidade do Vale do Rio dos Sinos, 2009.

MAROSTEGA, Vera Lucia. Os currículos de formação de professores para surdos na UFSM: A educação especial como campo do saber (1962-2009). 174 f. Tese (Doutorado em Educação) - Programa de Pós-Graduação em Educação, Universidade do Vale do Rio dos

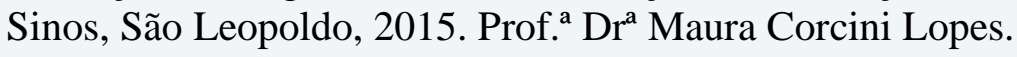

MARTINS, Alexandra da Costa Souza. Características desejáveis em professores de alunos com Altas Habilidades/Superdotação. 62 p. Dissertação (Mestrado em Educação) Universidade Católica de Brasília, 2010. 
MARTINS, Claudete da Silva Lima. Navegando no universo da Educação a Distância e nas redes dialógicas que a constituem: com a palavra as alunas do Curso de Formação Docente em Educação Especial da UFSM. 108 p. Dissertação (Mestrado em Educação) Universidade Federal de Pelotas, 2007.

MASET, Pere Pujolàs. Aulas inclusivas e aprendizagem cooperativa. In: RODRIGUES, David. Educação Inclusiva Dos conceitos às práticas de formação. 2011. Lisboa: Instituto Piaget. p. 45-88.

MATOS, Neide da Silveira Duarte de. A educação especial e a formação de professores proposta pelo programa "Educação Inclusiva: direito à diversidade". 153 p. Dissertação (Mestrado em Educação) - Universidade Estadual do Oeste do Paraná, 2011.

MEIRIEU, Philippe. Carta a um jovem professor. Porto Alegre: Artmed, 2006.

MEIRIEU, Philippe. O cotidiano da Escola e da Sala de Aula: o fazer e o compreender. Porto Alegre: Artmed, 2005.

MONTEIRO, Francisca Keyle de Freitas Vale. Formação de professores em sistema de comunicação alternativa para pessoas com transtorno do espectro autista - TEA: uma inserção das tecnologias assistivas em contextos escolares maranhenses. $155 \mathrm{f}$. Tese (Doutorado) - Programa de Pós-Graduação em Informática na Educação, Universidade Federal do Rio Grande do Sul, Porto Alegre, 2016. Prof. Dr. Dante Augusto Couto Barone.

NASCIMENTO, Simone do Socorro Freitas do. Representações sociais de professores sobre formação continuada em educação especial. 170 p. Dissertação (Mestrado em Educação) - Universidade Estácio de Sá, 2008.

NOZI, Gislaine Semcovici. Análise dos saberes docentes recomendados pela produção acadêmica para a inclusão escolar de alunos com necessidades educacionais especiais. 181 f. Dissertação (Mestrado em Educação) - Departamento de Educação, Universidade Estadual de Londrina, Londrina, 2013.

NUNES, Camila Almada. A formação continuada do docente para atuar na perspectiva da inclusão: a busca de contribuições para a prática pedagógica do professor da escola regular. 163 f. Dissertação (Mestrado em Educação) - Programa de Pós-Graduação em Educação. Universidade Estadual do Ceará. Fortaleza, 2014.

NUNES, Nilta Moreira Braga. Formação continuada em educação inclusiva. $132 \mathrm{f}$. Mestrado (Dissertação em Educação) - Programa de Pós-Graduação em Psicologia. Mestrado/MAPSI, Fundação Universidade Federal de Rondônia, Porto Velho, 2013.

OLIVEIRA, Andréa Duarte de. Condições de formação continuada do Programa Educação Inclusiva: direito à diversidade. 109 p. Dissertação (Mestrado em Educação) Universidade Federal de Mato Grosso do Sul, 2012.

OLIVEIRA, Ivanilde Apoluceno; SANTOS, Tânia Regina Lobato dos. Um olhar sobre a Educação Inclusiva e a formação continuada docente. V Seminário Nacional de Pesquisa em Educação Especial: formação docente em foco. Anais... UFRGS, UFES, UFSCAR, SP, 2009. 
OLIVEIRA, Sílvia Sales. Formação continuada de professores e informática educativa na escola inclusiva. 186 p. Dissertação (Mestrado em Educação Especial) - Universidade Federal de São Carlos, 2002.

OTALARA, Aline Piccoli. A formação de professores para o trabalho com deficientes visuais: uma experiência inicial de colaboração a partir do desenvolvimento de materiais didáticos. 176 f. Tese (Doutorado em Educação Escolar) - Área de Concentração: Formação do Professor, Trabalho Docente e Práticas Pedagógicas, Faculdade de Filosofia, Ciências e Letras de Araraquara, Universidade Estadual Paulista "Júlio de Mesquita Filho", Araraquara, SP, 2014. Prof. a Dra Maria Júlia Canazza Dall'Acqua.

PAIXÃO, Elaine Cristina. Formação de professores do Atendimento Educacional Especializado para alunos surdos em São Bernardo do Campo. 262 f. Dissertação (Mestrado) - Programa de Pós-Graduação em Educação, Universidade de São Paulo, São Paulo, 2016.

PAVAN, Daniela; DAMINATO, Alda. Costruire l'integrazione scolastica attraverso l'apprendimento cooperativo. In: CANEVARO, Andrea.; IANES, Dario. (a cura di). Buone prassi di integrazione scolastica. 20 reallizzazioni efficaci. Trento, Itália: Erickson, 2002. p. 84-104.

PEIXINHO, Márcia Alexandra Araújo. Formação continuada na perspectiva colaborativa para professores que atuam com alunos público-alvo da educação especial. $140 \mathrm{f}$. Dissertação (Mestrado) - Programa de Pós-Graduação em Formação de Professores da Educação Básica, Mestrado Profissional em Educação, Universidade Estadual de Santa Cruz, Ilhéus/Bahia, 2016.

PIOVEZANI, Márcia Ionara Eichstadt. Formação de professores e o atendimento ao aluno com deficiência no ensino regular na perspectiva da educação inclusiva. Dissertação (Mestrado em Educação) - Programa de Mestrado em Educação. Universidade Estadual do Oeste do Paraná, Paraná, 2013.

POSSA, Leandra Boer. Formação em Educação Especial na UFSM: estratégias e modos de constituir-se professor. 239 p. Tese (Doutorado) - Centro de Educação, Programa de PósGraduação em Educação, Universidade Federal de Santa Maria, Santa Maria, 2013. Prof. ${ }^{a}$ Dr $^{a}$ Maria Inês Naujorks.

QUEIROZ JR., Edison de. Formação Continuada de Professores para o Atendimento Educacional Especializado: Desafios e Perspectivas. 117 p. Dissertação (Mestrado em Educação). Faculdade de Educação, Universidade de São Paulo, 2010.

RABELO, Lucélia Cardoso Cavalcante. Ensino colaborativo como estratégia de formação continuada de professores para favorecer a inclusão escolar. $200 \mathrm{f}$. Dissertação (Mestrado em Educação) - Universidade Federal de São Carlos, São Carlos, 2012.

RABELO, Lucélia Cardoso Cavalcante. Casos de ensino na formação continuada à distância de professores do Atendimento Educacional Especializado. Tese (Doutorado) Programa de Pós-Graduação em Educação Especial do Centro de Educação e Ciências 
Humanas, Universidade Federal de São Carlos, São Carlos, 2016. Orientadora: Prof ${ }^{a}$. Dr ${ }^{a}$ Enicéia Gonçalves Mendes.

REGIANI, Erika Aparecida. Formação, percepções e práticas de professores especialistas em educação especial que atuam como regentes em classes inclusivas. $146 \mathrm{f}$. Dissertação (Mestrado em Educação) - Centro de Educação, Comunicação e Artes, Programa de pósgraduação em educação, Universidade Estadual de Londrina, Londrina, 2009.

REIS, Juliana Irani Villanueva dos. Processo de formação para professores de sala de recurso multifuncionais sobre as tecnologias assistivas para alunos com necessidades educacionais especiais. 71 f. Dissertação (Mestrado) - Programa de Pós-Graduação em Ensino de Ciências Humanas, Sociais e da Natureza, Mestrado Profissional, Universidade Tecnológica Federal do Paraná, Londrina, 2016. Prof. Dr. Vanderley Flor da Rosa.

RIBEIRO, Ana Claudia de Freitas. A escola como tempo e espaço na formação continuada para a inclusão escolar: o instituído e o instituinte. 68 p. Dissertação (Mestrado em Educação) - Universidade Federal de Santa Maria, 2008.

ROZEK, Marlene. As histórias de vida e a formação de professores. IV Seminário Nacional de Pesquisa em Educação Especial: conhecimentos \& margens. Anais... UFRGS, UFES, Gramado, RS, 2008.

Percursos de formação - uma perspectiva de formação docente. V Seminário Nacional de Pesquisa em Educação Especial: formação docente em foco. Anais... UFRGS, UFES, UFSCAR, SP, 2009.

SÁ, Nathalia Araújo. Políticas públicas de educação inclusiva: formação de professores e experiências do atendimento educacional especializado (AEE) no município de Nova Iguaçu/RJ. 134 f. Dissertação (Mestrado em Educação) - Faculdade de Educação,

Universidade Federal Rural do Rio de Janeiro, Seropédica, 2014.

SILVA, Eliana Formação de professores em educação especial: a experiência da UNESP Campus de Marília - SP. 116 f. Dissertação (Mestrado em Educação) - Faculdade de Filosofia e Ciências, Universidade Estadual Paulista Júlio de Mesquita Filho, Campus Marília, São Paulo, 2009. Prof. ${ }^{a}$ Dr $^{\mathrm{a}}$ Anna Augusta Sampaio de Oliveira.

SILVA, João Henrique da. Formação de professores para o Atendimento Educacional Especializado em escolas indígenas. 250 f. Dissertação (Mestrado em Educação) Programa de Pós-Graduação em Educação da Universidade Federal da Grande Dourados, Dourados-MS, 2014. Prof ${ }^{a}$. Dra . Marilda Moraes Garcia Bruno.

SILVA, Josenildo Pereira da. Formação docente em tempos de educação inclusiva: cenários e desafios em uma escola pública. 127 f. Mestrado (Dissertação em Educação) Programa de pós-graduação Educação. Universidade Federal do Rio Grande do Norte, Natal, 2014.

SILVA, Maria Elena Neves da. Formação e saberes: os desafios da docência na educação especial. Dissertação (Mestrado em Educação nas Ciências). Universidade Regional do Noroeste do Estado do Rio Grande do Sul, Ijuí/RS, 2014. Prof ${ }^{a}$. Dr ${ }^{a}$ Helena Copetti Callai. 
SILVA, Márcia Rodrigues da. A formação de professores de atendimento educacional especializado de Goiás. 208 f. Dissertação (Mestrado) - Programa de Pós-Graduação em Educação, Universidade Federal de Goiás, Campus Catalão, Catalão, 2014.

SILVA, Mayara Costa da. Formação continuada e educação especial: a experiência como constitutiva do formar-se. 125 f. Dissertação (Mestrado) - Programa de Pós-Graduação em Educação, Universidade Federal do Rio Grande do Sul, Faculdade de Educação, Porto Alegre, Rio Grande do Sul, 2015.

SILVA, Sérgio Carlos da. Educação especial: formação de professores e aprendizagem da docência dos professores que atuam em sala de recursos. 151 p. Dissertação (Mestrado em Educação) - Universidade Federal do Mato Grosso, 2008.

SILVA, Sônia Carla Gravena Cândido da. Formação docente para os desafios da educação inclusiva: um estudo a partir das Salas de Recursos Multifuncionais em Porto Velho/RO. 111 f. Mestrado (Dissertação em Educação) - Programa de pós-graduação em Educação. Universidade Federal de Rondônia, Porto Velho, 2014.

SILVA, Taciana Angelica Lopes. Educação Inclusiva e formação continuada de professores através da EAD: A experiência da UFAL. 100 p. Dissertação (Mestrado em Educação) - Universidade Federal de Alagoas, 2010.

SILVA, Wanda Lúcia Borsato da. Políticas públicas de educação, formação de professores e inclusão de alunos com necessidades educacionais especiais: as experiências da rede pública municipal de ensino de Petrópolis/RJ. 166 f. Dissertação (Mestrado em Educação) Programa de Mestrado em Educação. Universidade Federal Fluminense, Niterói, 2013.

SOUZA, Tanya Cecília Bottas de Oliveira e. Análise de uma proposta de formação continuada de professores no contexto da diversidade. 318 p. Dissertação (Mestrado em Educação) - Universidade de São Paulo, 2008.

V SNPEE. V Seminário Nacional de Pesquisa em Educação Especial: Formação de Professores em Foco. Apresentação nos Anais do Evento. São Paulo, n. 5, 2009. CD-ROM.

VALADÃO, Gabriela Tannús. Inclusão escolar e planejamento educacional

individualizado: avaliação de um programa de formação continuada para educadores. $248 \mathrm{f}$. Tese (Doutorado em Educação) - Faculdade de Educação, Universidade Federal de São Carlos, São Carlos, 2013.

VIEIRA, Scheila de Castro Abbud. Formação continuada do professor: um estudo das contribuições do programa conhecer para acolher para a prática pedagógica inclusiva. $123 \mathrm{p}$. Dissertação (Mestrado em Educação) - Universidade Federal do Pará, 2010.

VILARONGA, Carla Ariela Rios. Colaboração da educação especial em sala de aula: formação nas práticas pedagógicas do coensino. 216 f. Tese (Doutorado) - Programa de PósGraduação em Educação Especial do Centro de Educação e Ciências Humanas da Universidade Federal de São Carlos, São Carlos, 2014. 


\section{SOBRE AS AUTORAS:}

\section{Mayara Costa da Silva}

Doutoranda em Educação pela Universidade Federal do Rio Grande do Sul (UFRGS). Professora da Educação Especial no Colégio de Aplicação da UFRGS. Porto Alegre, RS. Pesquisadora do NEPIE-UFRGS. E-mail: mayacsilva@ gmail.com

iD http://orcid.org/0000-0001-8716-0768

\section{Clarissa Haas}

Doutora em Educação pela Universidade Federal do Rio Grande do Sul (UFRGS). Professora da área de Pedagogia no Instituto Federal do Rio Grande do Sul (IFRS). Caxias do Sul, RS. Pesquisadora do NEPIE-UFRGS.E-mail: cla.haas@ hotmail.com.

iD http://orcid.org/0000-0002-8526-7200

Recebido em: 10 de setembro de 2018

Aprovado em: 24 de agosto de 2019

Publicado em: 03 de dezembro de 2019 